\title{
Redefinindo a base teórica para o estudo dos partidos social-democratas
}

\author{
Refining the theoretical basis for the study \\ of social democratic parties
}

Guilherme Simões Reis*

\begin{abstract}
Resumo: A ciência política geralmente interpreta a social-democracia como moderação, adesão ao capitalismo e diferenças apenas residuais em relação ao liberalismo de mercado. Este artigo advoga por outra definição, baseada nas ideias de Kautsky e Bernstein, com dois elementos-chave: a importância central da democracia representativa e parlamentar e o reconhecimento de que há limites para avançar na transformação social. O reformismo gradual que daí decorre é o meio pelo qual os partidos social-democratas buscam melhorar a vida de trabalhadores e excluídos. É discutida a dinâmica interna dos partidos social-democratas, cuja tensão entre o pragmatismo "bernsteiniano" e o purismo "kautskiano" evita que a social-democracia vá para um dos extremos e se descaracterize. Debate-se o significado da moderação da social-democracia, a qual deve avançar no limite das possibilidades e lutar para modificar tais limites. Ao pesquisador cabe avaliar esses avanços relativamente aos limites e as ações realizadas para reduzir tais restrições.
\end{abstract}

Palavras-chave: Social-democracia; partidos; democracia representativa; Karl Kautsky; Eduard Bernstein

Abstract: Political Science uses to interpret social democracy as moderateness, adhesion to capitalism and only residual differences relatively to market liberalism. This paper advocates for another definition based on the ideas from Kautsky and Bernstein, containing two key elements: the core importance of representative and parliamentary democracy and the acknowledgement that there are constraints to the advancement of social transformation. The gradual reformism which results is the way social democratic parties use to pursue the improvement of the workers' and excluded people's lives. I discuss the internal dynamics of the social democratic parties, whose tension between "Bernsteinian" pragmatism and "Kautskyan" purism avoids that social democracy moves to one of the two extremes and loses its traits. I debate the meaning of moderateness in social democracy, which shall advance as far as possible and fight to transform the constraints. If that is happening it is what researchers shall investigate.

Keywords: Social democracy; parties; representative democracy; Karl Kautsky; Eduard Bernstein

* Professor de Ciência Política da UniRio. Doutorando em Ciência Política pelo Iesp-Uerj. <greis@iesp.uerj.br>.

\begin{tabular}{|c|c|c|c|c|c|}
\hline Civitas & Porto Alegre & v. 12 & n. 2 & p. 321-339 & maio-ago. 2012 \\
\hline
\end{tabular}




\section{Introdução}

O mais nobre no Socialismo é justamente que ele não é o regime da minoria. Ele não pode, portanto, e não deve ser imposto por uma minoria.

JEAN JAURÈS

Este trabalho está voltado para a elaboração de bases teóricas para analisar a social-democracia - e mais especificamente os partidos social-democratas, especialmente quando estes estão no governo - contemporaneamente e/ou ao longo do tempo. Não se pretende aqui, portanto, realizar uma avaliação empírica de governos comumente chamados de social-democratas, mas sim propor uma abordagem original para que estudos desse tipo se desenvolvam de forma mais promissora. A proposta consiste na adoção de um método indutivo: tem-se uma definição prévia de social-democracia e parte-se dela para avaliar se os partidos e governos podem ser classificados como social-democráticos ou, no caso de uma trajetória menos clara e consistente, se ao menos algumas de suas políticas devem ser assim rotuladas.

Este objetivo tem implícitas duas premissas, as quais marcam um rompimento com formas tradicionais de se abordar a questão. A primeira delas é a consideração de que o conceito de social-democracia é aplicável a diferentes épocas e contextos, e não apenas a uma época do tempo e lugar, a saber, o período entre a Segunda Internacional e o pós-guerra na Europa. A segunda é a de que a social-democracia deve ser tratada de modo semelhante ao que faziam autores como Karl Kautsky e Eduard Bernstein - como uma forma de política socialista que tem a democracia representativa eleitoral parlamentar como essencial e não meramente como instrumental - e não como tem sido abordada mais correntemente.

A presente crítica considera a forma recorrente de se analisar a socialdemocracia - que consiste em um método dedutivo - como muito próxima a uma sistematização do senso comum: moderação, defesa e adesão ao capitalismo, diferenças no máximo residuais em relação ao liberalismo de mercado, políticas equivalentes àquelas defendidas pelos neoliberais. De acordo com tal visão, haveria uma progressiva moderação desses partidos até não mais se diferenciarem dos adversários. A social-democracia seria, por definição, moderada, de "centro-esquerda", e implicaria mudanças superficiais.

Tal abordagem obscurece as diferenças entre direita e esquerda ou limita o escopo em que se percebe que a social-democracia pode atuar efetivamente. É por isso que este trabalho propõe outra abordagem, em que o conceito é 
desenvolvido a partir da ideia de social-democracia: a social-democracia é uma política socialista, partidária, que visa a avançar na transformação do sistema produtivo, de modo a torná-lo mais favorável aos trabalhadores (não apenas o operariado fabril ${ }^{1}$ ) e excluídos, que formam sua base eleitoral prioritária (core constituency). Contrariamente aos partidos comunistas, ou marxista-leninistas, os social-democratas, ou socialistas democráticos, destacam a importância central da democracia representativa e parlamentar. Ao refutarem a opção pela revolução violenta (revolução, aqui, não tem o significado de transformação profunda da ordem, pois a premissa é justamente a de que esta pode ser realizada pela via institucional), reconhecem que há limites conjunturais para esse avanço, que impactam em sua velocidade.

Tal abordagem é consistente com as reflexões de teóricos da socialdemocracia desde suas origens, na Segunda Internacional, ${ }^{2}$ e diverge de avaliações de que a social-democracia deva ser entendida como um movimento em contínua mutação - "antes era uma coisa, agora seria outra" -, que pouco ou nada tem em comum nos diferentes pontos do tempo, salvo o rótulo (cujo único fundamento, portanto, seria a tradição: quem originalmente era socialdemocrata para sempre será considerado como social-democrata).

A social democracia, como é aqui compreendida, pode inclusive ser representada como uma tensa síntese das ideias de Karl Kautsky e Eduard Bernstein. Ambos concordam com todos os pontos anteriormente destacados, mas apresentam discordâncias que estão presentes no interior de qualquer partido social-democrata, dividido em uma ala mais pragmática e outra mais purista. A questão será analisada em uma seção específica.

Não se trata de uma visão ingênua e voluntarista de que todos os partidos ditos social-democratas efetivamente agem com a motivação de transformar a sociedade favorecendo os trabalhadores. Ao contrário, é uma abordagem muito mais exigente: caso eles não façam isso, é necessário que não sejam classificados como social-democratas. A forma como um partido se denomina não o define: há partidos que se chamam de social-democratas que dificilmente poderiam ser assim classificados, enquanto outros que adotam outros nomes ou mesmo rejeitam o termo parecem se adequar mais a essa denominação.

1 Uma abordagem da social-democracia que não a considere um conceito unicamente aplicável a um período passado não poderia anacronicamente excluir da base eleitoral dos partidos social-democratas outros grupos de trabalhadores que não o operariado. A ênfase de autores clássicos nesse grupo específico de trabalhadores fazia sentido em sua época, mas hoje deve ser expandida.

2 Considero, aqui, que o socialismo da Primeira Internacional é prévio à social-democracia, configurando-se tanto ela como o marxismo-leninismo como duas variantes daquele mesmo socialismo de matriz marxiana. 
Além disso, partidos podem sofrer mudanças ideológicas ao longo do tempo: um partido pode, por exemplo, ser originalmente marxista-leninista, depois se converter em social-democrata e, posteriormente, tornar-se liberal.

Em muitos casos, as conclusões resultantes da aplicação da abordagem aqui sugerida podem, inclusive, convergir com aquelas presentes nas pesquisas desenvolvidas dentro das bases que aqui são criticadas. Avaliações impressionistas, entretanto, não contribuem para um diagnóstico adequado; há que se analisar as medidas adotadas pelos governos de partidos social-democratas e as limitações que eles enfrentam, conforme será discutido neste texto.

Gramsci chama a atenção para o papel da hegemonia, por meio da qual os interesses do grupo dominante, aquele cuja ideologia prevaleceu no confronto das ideologias, são vistos como coordenados com os interesses dos grupos subordinados (Sader, 2005). Aí está tanto um perigo como uma missão para a social-democracia. O perigo é o de os partidos tidos como social-democratas não atuarem de modo realmente social-democrático, isto é, não defendendo os interesses dos trabalhadores ou excluídos, ao menos não quando estes representarem uma ameaça aos interesses do capital. A missão dos socialdemocratas é agir para que prevaleça uma nova ideologia, alcançando apoio para sua plataforma e um ambiente mais favorável. Os partidos realmente social-democratas avançam no limite das possibilidades e trabalham para reduzir essas limitações à plataforma socialista.

A melhoria das condições de vida dos trabalhadores e excluídos em geral passa não apenas por lhes garantir uma renda suficiente para uma boa vida, mas também pela desmercantilização dos indivíduos frente ao mercado, ou seja, pela sua emancipação da dependência do mercado. Os direitos sociais devem estar relacionados à cidadania e não à eficiência ou à produtividade do indivíduo no mercado, não ao seu poder de pagar uma contribuição (EspingAndersen, 1985 e 1990).

Na próxima seção serão abordados a visão predominante sobre a socialdemocracia e o importante papel desempenhado por Przeworski (1989) em sua sistematização. Em seguida, será realizado o contraponto, apresentando-se o conceito de social-democracia aqui proposto, sua relação com o pensamento de Kautsky e Bernstein, a dinâmica interna dos partidos social-democratas e, por fim, uma conclusão acerca do significado da moderação da social-democracia e o desafio que ela impõe ao pesquisador.

\section{A visão predominante sobre a social-democracia}

O senso comum basicamente repete a sistematização realizada por Przeworski (1989). Sua análise oferece uma importante contribuição para o 
entendimento do momento inicial de expansão e fortalecimento dos partidos social-democratas na Europa. Ele narra o processo de adesão e defesa da democracia, seguidos pela opção pela reforma em detrimento da tese da revolução e pela aceitação de alianças, passando a social-democracia a se pautar pelas melhorias gradativas e cumulativas. É de grande utilidade sua constatação de que a única política econômica que os partidos socialistas tinham em seu programa de governo era a nacionalização da indústria, de modo que, quando venceram pela primeira vez as eleições, só lhes restou adotar as mesmas políticas econômicas ortodoxas dos adversários, apenas com um pouco mais de política social, e que isso mudou a partir da adoção do Keynesianismo desde os anos 1930, com o intuito de redefinir o papel do Estado.

Przeworski, no entanto, tira conclusões questionáveis quando afirma categoricamente que há uma mudança nos objetivos dos partidos socialdemocratas e, pior, considera isso como um traço característico da socialdemocracia. O cientista político polaco-estadunidense sistematizou a trajetória da social-democracia sob uma perspectiva determinista.

Ele afirma que o abandono do capitalismo deixou de ser o objetivo da social-democracia, sendo substituído por sua humanização. Essa aceitação do capitalismo, segundo ele, implicaria a necessidade de que as intervenções do Estado devessem se pautar pela eficiência econômica, de modo que os partidos social-democratas teriam passado a se preocupar mais com o abrandamento dos seus efeitos perversos do que com o próprio reformismo, que teria perdido seu caráter cumulativo.

Esping-Andersen (1985, p. 14) classifica a argumentação de Przeworski como "uma variação mais sutil e sofisticada de leninismo". Przeworski não negaria a possibilidade de a social-democracia parlamentar conseguir a maioria necessária para a transformação socialista; justamente nesse momento histórico, no entanto, segundo o autor, ela encontraria sua derrota, sobrecarregada com demandas populares que não poderiam ser atendidas sem desestabilizar a economia e sem provocar crises incontroláveis.

A tese da diluição ideológica da social-democracia antecede a obra de Przeworski. Manin (1989) constata que ela se difundiu já nos anos 1960, a partir da tese de Kirchheimer (1966) da "americanização" dos partidos social-democratas. Manin, no entanto, recusa que o objetivo final é abandonado na social-democracia. Para ele, o objetivo final continua existindo, como um tipo de ideia reguladora, de guia para as ações. O conceito de socialdemocracia adotado neste artigo se identifica mais com Manin do que com Przeworski. 
$\mathrm{O}$ argumento de mudança de objetivo da social-democracia, que ecoa no senso comum, está presente tanto em autores liberais, que aplaudem a esquerda por sua suposta domesticação, como em marxistas, como Coelho (2001), que a tratam como traidora. Mais rica é a análise de Panizza (2005) da "social-democratização" da esquerda brasileira, uruguaia e chilena. Ele dá a atenção devida às limitações - era do capital móvel e financeiro, sindicatos enfraquecidos, baixo número de trabalhadores industriais - e ao respeito às instituições democráticas na busca por reformas. Também está atento às possibilidades de aprofundamento das instituições democráticas e à mudança radical na vida da população que a produção de empregos e a melhoria dos serviços públicos significariam.

Ainda assim, no entanto, Panizza caracteriza o posicionamento da socialdemocracia como uma guinada do radicalismo para a "centro-esquerda", como se o não-rompimento (imediato) com o capitalismo - e sim a sua limitação e correção - inviabilizasse a classificação como "esquerda".

\section{Outra abordagem sobre os partidos social-democratas}

Há, na presente definição de social-democracia derivada da síntese de Kautsky e Bernstein, um consenso quanto à importância central da democracia representativa e parlamentar e quanto ao reconhecimento de que há limites conjunturais (ou estruturais mas, ainda assim, alteráveis) para se avançar na transformação do sistema produtivo, de modo a torná-lo mais favorável aos trabalhadores e excluídos, que formam sua base eleitoral prioritária (core constituency).

Como os limites mudam com o tempo e de caso para caso, e o reconhecimento (e enfrentamento pela via institucional) dos limites é parte essencial da própria social-democracia, o próprio conceito é aplicável a diferentes contextos, épocas e lugares. Os próprios Kautsky e Bernstein chamavam a atenção para os diferentes limites existentes em cada país ou sociedade. Bernstein (1997, p. 126) é particularmente explícito em relação a isso. $^{3}$

As tarefas de um partido estão determinadas por uma multiplicidade de fatores: pela posição do desenvolvimento geral, econômico, político, intelectual e moral, na esfera da sua atividade, pela

\footnotetext{
3 Kautsky também tem em mente as diferentes limitações, pois destaca os variados graus de conquistas de parcelas de democracia pelas classes trabalhadoras e de amadurecimento destas (Kautsky, 1971) e observa que diferentes costumes, instituições e históricos de democracia e de direitos conquistados levam a uma maior ou menor possibilidade (e rapidez) de que a transição para o socialismo ocorra por pacíficos meios econômicos, legais e morais, em vez de pela força física e militar (Kautsky, 1979).
} 
natureza dos partidos que atuam a seu lado ou contra ele, pelo caráter dos meios que estão no seu comando e por uma série de fatores objetivos e ideológicos, a cuja frente se situam a principal finalidade do partido e a sua concepção do melhor caminho para atingir essa finalidade.

Trata-se de um tipo de socialismo em que as instituições democráticas liberais são vistas como um instrumento para as políticas socialistas e em que o Estado é concebido como uma instituição não necessariamente antiproletária, pois muda seu caráter quando os representantes do povo estão no poder. $\mathrm{O}$ reformismo gradual que daí decorre é adotado em meio a um conflito interno nos partidos social-democratas entre o pragmatismo "bernsteiniano" - que, por não ter objetivos de longo prazo definidos, por vezes se confunde com os adversários da direita - e o purismo "kautskiano" - que recusa alianças que não apenas não impediriam, como até viabilizariam reformas profundas.

A social-democracia seria, portanto, herdeira da Segunda Internacional, ${ }^{4}$ na qual continuaram tanto os "ortodoxos" democráticos como os revisionistas - estes, apesar de condenados no discurso, acabaram por predominar na prática dos partidos social-democratas. A social-democracia contrasta, dentro do campo socialista, com os comunistas - os quais romperam com a Segunda Internacional para formar a Comintern, a Terceira Internacional, condenando a rejeição à revolução violenta e a defesa da "democracia burguesa" como "deformações" do marxismo. Como observa Andreucci (1982), aquela foi uma fratura dramática no movimento operário, muito mais significativa do que as divergências entre ortodoxos e revisionistas no seio do Partido Socialdemocrata Alemão, que tinha como norma interna ampla "liberdade de crítica".

A referência a Kautsky e Bernstein, dois teóricos de origem marxista de contato muito próximo com Engels, na apresentação deste conceito de socialdemocracia não significa ignorar que a social-democracia não tem o marxismo como única base teórica. É necessário ter em vista que ela incorporou muitas outras influências, como a do socialismo utópico, a do socialismo cristão e a de diferentes tradições econômicas. Esse ecletismo, que foi duramente condenado por muitos marxistas favoráveis à revolução violenta, é nítido em Bernstein, bastante influenciado pelo contato com a socialista Sociedade Fabiana britânica, particularmente com o casal Sidney e Beatrice Webb (Kloppenberg, 1986).

4 Andreucci (1982, p. 18) diz que não há uma "estrita continuidade com a Segunda Internacional" no marxismo não-comunista, havendo, na verdade, casos de inovação, como o austromarxismo. Ele reconhece, porém, que as inovações eram em parte "resultado de uma seleção muito atenta no âmbito das tradições da Segunda Internacional". 


\section{Proximidades e divergências entre Kautsky e Bernstein}

Este trabalho vê a social-democracia como uma tensa síntese das ideias dos "teóricos fundadores" Karl Kautsky e Eduard Bernstein. Afinal, como afirma Esping-Andersen (1985, p. 17): “A teoria social-democrata moderna deriva da controvérsia entre o reformismo marxista, exemplificado por Kautsky, e o revisionismo de Bernstein."

Kautsky via a política dentro da lógica da luta de classes e, por isso, ele se opunha a alianças com os partidos burgueses, salvo em casos excepcionais e em períodos breves. ${ }^{5}$ Parcerias dos proletários com camponeses e intelectuais eram bem-vindas, mas não poderiam implicar qualquer alteração no programa do partido social-democrata. Kautsky defendia a adesão ao sistema representativo e eleitoral e, inclusive, o respeito pela existência e atuação de partidos adversários, burgueses, mas considerava inaceitável uma composição com eles. Para ele, o proletariado deveria atuar na democracia como oposição, até que, maduro e numeroso o suficiente, fosse capaz de atingir a maioria no parlamento e, então, levar adiante a "revolução social" (Salvadori, 1982; Waldenberg, 1982). A ideia de "revolução", aí, está dissociada tanto de violência como de rapidez, e diz respeito apenas à profundidade da transformação (Przeworski, 1989; Manin, 1989).

Kautsky não abandona a ideia de derrubar o capitalismo e de substituí-lo pela ordem de produção socialista, mas vê na democracia representativa um meio eficiente de atingir tal objetivo - que necessariamente viria a ocorrer, de acordo com sua teoria determinista -, ainda que de forma lenta, sem desperdício de forças. Como observa Manin (1989), a oposição que marca a diferença entre a cultura social-democrata pacífica e a leninista violenta é a do curto e do longo prazo.

Para Bernstein, por outro lado, a democracia não só é o meio para o socialismo, como também é o fim, pois o fim é sempre construído, não podendo ser definido ex ante. Segundo Bernstein (1997, p. 126), "Sem uma determinada quantidade de instituições ou tradições democráticas, [...] Haveria, por certo, um movimento operário, mas não uma social-democracia."

Contrariamente a Kautsky - que vê uma inevitabilidade da democracia em direção ao socialismo, assim como a disputa política como um jogo de soma

Conforme observa Salvadori (1982), Kautsky mudaria de opinião quanto aos governos de coalizão, defendidos por ele abertamente em seu $A$ revolução proletária e seu programa, publicada em 1921, três anos depois de $A$ ditadura do proletariado. Entretanto, em quase todo o período de maior influência intelectual do autor, ele defendeu uma adesão pacífica à democracia liberal sem qualquer concessão política aos burgueses, encarando as eleições e disputas parlamentares como uma arena preferencial da luta de classes. 
zero, em que quem tem a maioria para vencer as eleições implementa o seu programa -, Bernstein é cético em relação a essa uniformização. Ele defende justamente a incorporação das camadas médias como aliadas, o que faz sentido em sua concepção ética de socialismo, não deduzida do materialismo histórico (Waldenberg, 1982; Fetscher, 1982; Salvadori, 1982; Kloppenberg, 1986;6 Przeworski, 1989; Nettl, 1973-74).

Se por um lado as diferenças entre Kautsky e Bernstein são importantes e se reproduzem no interior dos partidos social-democratas até hoje, por outro a essência da social-democracia é o que suas visões de mundo têm em comum. Ambos defendiam a importância central da política parlamentar e do sufrágio universal. Já na redação do Programa de Erfurt, Kautsky (1971) afirmava que, quando os trabalhadores começam a fazer parte da política parlamentar, ela tem sua própria natureza alterada; passa a ser como uma arena da luta de classes sem violência, em que não havia desperdício de tempo e energia de nenhuma das duas partes, pois ambas viam, como em um termômetro, o seu grau de apoio e sua capacidade de avançar nas mudanças ou de freá-las.

Kautsky diz que não é possível o socialismo existir sem democracia, porque, na ausência dela, ele não emancipa o proletariado, não cumpre o objetivo final: a meta é a "revolução social", isto é, uma profunda transformação da sociedade, com a eliminação da opressão e da exploração - e não uma mera troca de quem está no poder, à semelhança das revoluções burguesas e do regime soviético. Essa "revolução social" é necessariamente gradual e lenta, deve ser aceita pela maioria da população - o que ocorrerá quando ela estiver madura para o socialismo - e não imposta por uma minoria que se intitule detentora do conhecimento. Assim, segundo Kautsky (1979, p. 37), é necessário que "a revolução social se submeta aos princípios de ação da democracia; isto é, que a revolução social não vá além do ponto a que a maioria da massa do povo está determinada a ir".

Bernstein (1997, p. 114), por sua vez, como não tinha as certezas de Kautsky acerca de um triunfo socialista, valorizava mais a experimentação,

\footnotetext{
6 Kloppenberg não enfatiza a adesão à democracia e sim outros elementos em sua definição de social-democracia, que, por vezes, é contraposta ao marxismo. Aspectos presentes em Bernstein, e que o autor reconhece em pensadores que segundo ele seriam os representantes teóricos social-democratas na França, no Reino Unido e nos Estados Unidos, são os tópicos que ele identifica como definidores da social-democracia: empiricismo, reconhecimento da impossibilidade de se ter certezas sobre o futuro, idealismo e ética em vez de materialismo. Kautsky, segundo ele, não seria nem um social-democrata, nem um revolucionário, e estaria espremido entre os dois, no centro do Partido Social-democrata da Alemanha. Kloppenberg, no entanto, considera Jean Jaurès como o representante por excelência da social-democracia francesa e, ao mesmo tempo, afirma que ele está ideologicamente mais próximo de Kautsky do que de Bernstein.
} 
fundamental em função das incertezas da política, e, para ele, o ambiente democrático é o mais propício para ela, por meio do conflito de ideias e de interesses. Bernstein observa que o sufrágio universal é "útil aos exploradores, como Bismarck", quando os trabalhadores não têm discernimento, mas, quando têm, ele é "seu terror", concordando com Kautsky que, a partir da organização deles, o sistema representativo com sufrágio universal mudou seu caráter. Se, inicialmente, "o direito geral a voto pode parecer-se muito com o direito de escolher 'o carrasco'; com o número crescente e o maior discernimento dos trabalhadores, a situação mudou".

Como Kautsky, Bernstein também vê a democracia como um termômetro pelo qual os partidos e classes sabem até onde ir sem correrem maiores riscos. Ele diz que a democracia é a "escola superior do compromisso", e que os partidos e as classes sociais que estão por trás deles conhecem seus limites, sabem até onde ir de acordo com as circunstâncias do momento, moderam-se, mesmo que, às vezes, façam exigências superiores ao que seriamente pensam.

Bernstein (1997, p. 125) dá o importante passo de explicitar que as instituições liberais não são contrárias ao socialismo, bastando que elas sofram ajustes para que os trabalhadores sejam beneficiados: "As organizações liberais da sociedade moderna distinguem-se daquelas [das organizações feudais] precisamente pela sua flexibilidade e sua capacidade de transformação e desenvolvimento. Não precisam ser destruídas, mas apenas ser desenvolvidas."

Em síntese, ambos enfatizam a necessidade de aceitar e participar da democracia representativa, inclusive admitindo a atuação dos partidos burgueses, rejeitam o uso da violência (a não ser para se defender, justamente, de um ataque autoritário das forças reacionárias), chamam a atenção para a mudança do caráter da democracia liberal a partir da atuação do partido socialdemocrata, e reconhecem que há limites para uma transformação socialista rápida.

\section{A dinâmica da social-democracia}

Ao invés da adoção da ideia de que a social-democracia é um movimento passivo, é mais construtivo analiticamente e superior normativamente incorporar como premissa analítica o comprometimento com a transformação da sociedade, que era um ponto essencial tanto para Kautsky como para Bernstein. Isso lança luz, inclusive, sobre as possibilidades das instituições políticas liberais, ofuscadas em abordagens procedimentalistas reducionistas como, por exemplo, a de Riker (1982).

Mesmo as diferenças entre o pensamento de Kautsky e o revisionismo de Bernstein devem ser consideradas nesta abordagem dos partidos social- 
democratas e sua plataforma. Os dois elementos-chave citados - democracia representativa e reconhecimento de limites -, comuns a ambos, são características irredutíveis da social-democracia. Os pontos de antagonismo entre os dois teóricos são refletidos nas alas "purista" e "pragmática" de todos os partidos social-democratas, e a própria tensão entre elas é importante para o desenvolvimento da social-democracia.

Não está no escopo deste artigo discutir casos específicos, visto que o objetivo é unicamente o estabelecimento de bases teóricas mais abstratas para posteriores estudos mais concretos e empíricos. Entretanto, apenas para ilustrar, pode-se pensar tal tipo de conflito entre puristas e pragmáticos, por exemplo, no Partido Socialista Operário Espanhol (PSOE), no Partido dos Trabalhadores (PT), no Partido Trabalhista britânico e na Frente Ampla uruguaia, os quatro partidos potencialmente classificáveis como social-democratas. No PSOE, na virada dos anos 1970 para os anos 1980, houve a disputa interna entre os socialistas mais à esquerda - que queriam a adoção de uma linha programática radical e a manutenção da cooperação com os comunistas - e o líder Felipe González e seu aliado Alfonso Guerra - que pretendiam retirar as referências ao marxismo existentes na plataforma do partido (Camiller, 1996). No interior do PT, após seu fracasso nas eleições de 1982, sua ala mais à esquerda se fortaleceu, e veio a assumir o controle partidário. Em resposta a essa mudança na correlação de forças, os moderados, como Lula e os outros sindicalistas, formaram em 1983 a tendência Articulação, que retomou o controle do PT em 1995 ao se fundir com a Democracia Radical, formando o Campo Majoritário (Singer, 2001). O Partido Trabalhista teve, nos anos 1990, conflitos do grupo de Tony Blair, que rebatizou o partido como "New Labour" e possuía um programa fortemente influenciado pela "terceira via", com seus adversários mais à esquerda, que ele chamou pejorativamente de "Old Labour" (Marlière, 2000). Na Frente Ampla uruguaia, há divergências entre a Frente Líber Seregni, que reúne os grupos mais centristas aliados do vice-presidente, Danilo Astori, e "frações" menos moderadas, como o Movimento de Participação Popular do presidente José "Pepe" Mujica, o Partido Socialista e, principalmente, o Partido Comunista Uruguaio, em torno de questões como a reforma tributária (Reis, 2011).

A definição como tensa síntese entre as alas "purista" e "pragmática" é análoga à tensão entre a lógica da representação das bases eleitorais e a lógica da competição eleitoral, presente na formulação de Kitschelt (1989) sobre a formação dos partidos políticos. A lógica da representação das bases eleitorais é inspirada pela ideologia e pelas práticas políticas de seus apoiadores. A opção pela lógica da competição eleitoral, por outro lado, implica o ajuste da 
organização interna, do programa e das estratégias às condições do "mercado político", para maximizar o apoio eleitoral. Quanto mais puro ideologicamente for o programa do partido, mais restrito é seu apelo eleitoral. Entre as duas opções polares haveria um continuum de possibilidades, da mesma forma, é claro, que há possibilidades intermediárias entre os tipos ideais "purista" e "pragmático" na teoria de social-democracia aqui sustentada.

Subjaz a perspectiva adotada neste trabalho a ideia de que há atores dentro dos partidos que querem que eles deem uma guinada para cada um dos extremos - o do purismo e o do pragmatismo -, e de que é a tensão entre eles que mantém o partido aproximadamente no meio, podendo tender um pouco para cada um dos lados.

Os dois pólos - purista e pragmático - estão vivos e em permanente disputa dentro dos partidos. Se um dos dois se enfraquecer demais, corre-se o risco de que o partido deixe de ser efetivamente social-democrata e se torne meramente office-seeking (interessado em postos de poder como fim último e não como meio de implementar determinadas políticas), ou de se isolar como um partido de gueto, que não é capaz de vencer eleições e, por isso, tem dificuldades ou mesmo a impossibilidade de influenciar a decisão acerca das políticas a serem adotadas.

Obviamente também podem levar a uma mudança de rumo dos partidos seus integrantes não classificáveis como social-democratas, como liberais, comunistas, ou puros office-seekers não-ideológicos, por exemplo. A entrada deles é frequentemente admitida, dada a frouxidão de critérios comumente empregada para as filiações e a maior liberdade interna, uma marcada diferença em relação aos partidos comunistas (Esping-Andersen, 1985). Isso também é um entrave à plataforma social-democrática e complexifica uma análise dos atores no interior do partido.

Dentro do esquema teórico de Strøm e Müller (1999), que separam os modelos comportamentais de partidos competitivos encontrados na literatura de ciência política em três tipos básicos - office-seeking, policy-seeking e vote-seeking -, a abordagem aqui proposta se enquadra no segundo tipo. Cada um dos três modelos tem uma diferente premissa sobre qual é o fim último do partido: obter cargos/participar do governo, implementar políticas de sua preferência, ou obter a maior votação possível. É claro que os três objetivos estão interligados - quem recebe mais votos consegue ser eleito e, no governo, implementa suas políticas - mas a ideia dos autores é a de que está mais ou menos explícita em cada teoria a premissa de que um dos três é o mais valorizado, tendo os demais uma função mais instrumental. Strøm e Müller (1999) veem como mais consistentes a abordagem policy- 
seeking, em que a política pública é o principal (seja pelo valor intrínseco da adoção de determinada política, seja pelo fato de ela garantir a manutenção de uma base eleitoral com tal preferência), e a abordagem office-seeking, em que objetivo central é chegar ao poder (mesmo que para isso se tenha que adotar uma política muito diferente daquela de sua preferência). A abordagem vote-seeking, apesar de dificilmente se poder entender voto com o fim último e não como apenas um meio de atingi-lo, enquadraria, por exemplo, o clássico Uma teoria econômica da democracia, de Anthony Downs (1999) [1965].

Cada uma das três abordagens pode ser a mais válida dependendo do objeto específico de cada pesquisa e do seu desenho. Sem qualquer recusa da utilidade da tradição na ciência política dos estudos que utilizam a premissa da reeleição como objetivo último do político, os quais são office-seeking, aqui se considera que, para a pesquisa específica sobre o quanto a esquerda democrática está trabalhando para transformar a sociedade, um modelo policyseeking é de maior utilidade. Assim, nesta abordagem, a premissa é a de que o principal objetivo (o fim ultimo) dos políticos social-democratas não é o de se reelegerem, ou o de formarem parte do governo, mas o de implementar políticas, ainda que ser eleito, bem como maximizar votos, sejam importantes para atingir essa meta.

O conceito de social-democracia aqui adotado tem como pontos essenciais a insubstituível opção pela via democrática das reformas e a compreensão de que estas são realizadas dentro das limitações existentes no país, com o intuito de transformar o capitalismo de modo a tornar o sistema produtivo mais favorável aos trabalhadores e excluídos. O foco é, idealmente, sempre a melhoria das condições de vida e de trabalho dos assalariados e dos desfavorecidos em geral, que formam sua base eleitoral prioritária (core constituency). As limitações são de vários tipos: correlação de forças entre os partidos políticos, heranças teóricas tradicionais específicas de cada partido social-democrata, necessidade ou não de formar coalizões com outros partidos, capacidade de intervir na legislação, poder econômico do país e sua inserção na economia internacional, grau de competências atribuídas ao Estado, proporção de clientes e potenciais apoiadores de políticas públicas social-democráticas etc.

O conceito de social-democracia aqui desenvolvido implica a transformação da sociedade dentro do que é aceito por ela, necessariamente - mas não unicamente - por meio da democracia eleitoral e parlamentar, na velocidade em que as condições possibilitem. Tal interpretação se identifica tanto com o revisionismo de Bernstein como com o que defendia Kautsky, para 
quem a "ditadura do proletariado" não significaria um governo autoritário e sim o resultado de uma vitória esmagadora nas urnas (Kautsky, 1979).

\section{O foco da análise: moderação ou limites?}

Moderação e pouca profundidade das reformas não seriam características da social-democracia em si, como supõe o senso comum, e sim resultados condicionados por uma determinada conjuntura. Como observa EspingAndersen (1990, p. 44), o que separa as alas reformista e revolucionária do socialismo é muito mais a questão da estratégia a se adotar do que seus objetivos.

A premissa das melhorias gradativas e cumulativas é fundamental para um conceito de social-democracia, mas não se pode ignorar o aspecto das limitações. Assim, uma redução na velocidade das reformas não significa necessariamente que elas se tornaram menos relevantes ou que foram abandonadas, como sugere Przeworski; elas simplesmente podem não ter condições conjunturais de avançar. Entretanto, é fundamental destacar: a conjuntura é, ela também, alterável pela ação dos diferentes atores em disputa. Conforme observa Esping-Andersen (1990, p. 32), reformas ocorridas no passado contribuem para o enraizamento de preferências de classe e de comportamentos políticos.

O sucesso de um partido social-democrata é sempre relativo às limitações com as quais ele se depara. Essa relação é ilustrada no Gráfico 1, a seguir. A linha inclinada define o que se espera de um partido socialdemocrata relativamente às limitações que ele enfrenta para promover um avanço socialista: quanto maiores forem as restrições, mais modestas são as expectativas de avanço.

O "fracasso" significa que o partido não avançou tanto quanto possível, seja porque não foi competente na identificação das oportunidades existentes e na elaboração e implementação das estratégias necessárias, seja porque não quis promover mudanças tão drásticas quanto as condições permitiam (neste último caso, o partido não pode ser classificado como social-democrata). Estudos no nível micro podem contribuir para o desafio de realizar esta diferenciação, para a qual o simples contraste entre limitações e resultados é insuficiente.

Também é possível, ainda que menos provável, que, com criatividade e extrema habilidade para negociar e convencer outros partidos de que o seu projeto também atende ao que eles almejam, o partido social-democrata seja capaz de avançar além do que seria esperado, tendo em vista as restrições existentes. 
Gráfico 1. Limitações $\times$ Sucesso do partido social-democrata

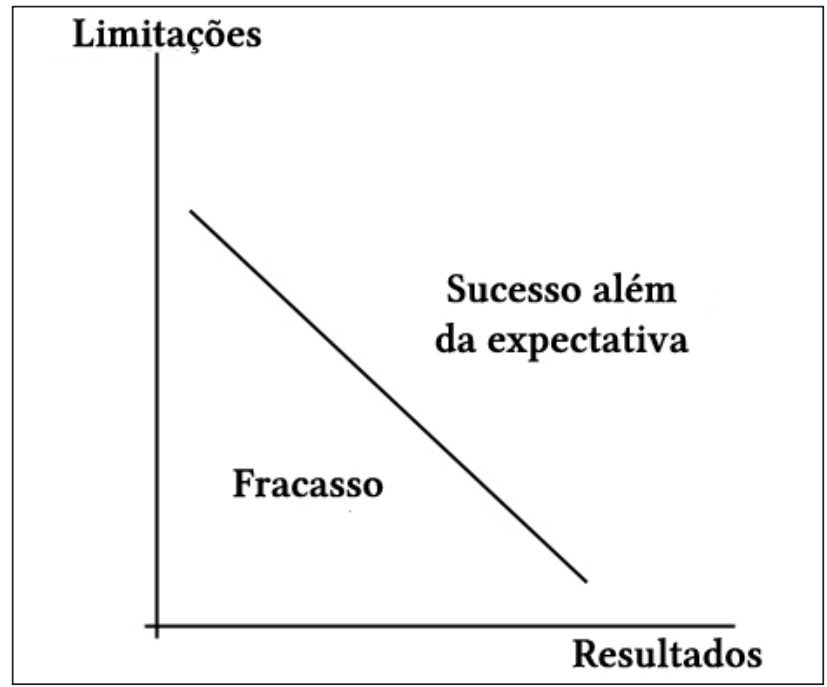

Fonte: o autor.

Conforme o observado na primeira seção, a existência de uma hegemonia pró-mercado, cuja ideologia apresenta os interesses do grupo dominante como coordenados com os interesses dos grupos subordinados, representa tanto um perigo como uma missão para a social-democracia. O perigo é o de que jogos de soma positiva, isto é, situações favoráveis em que todos são beneficiados, camuflem uma situação de manutenção de privilégios e das condições para a máxima expansão do grupo dominante, que permite um relativo atendimento dos interesses dos grupos subordinados, mas apenas até o ponto em que não haja transformações estruturais profundas e de natureza desmercantilizadora.

É missão do investigador, portanto, identificar, nos contextos em que chega ao limite o atendimento simultâneo aos interesses de grupos ligados ao mundo do trabalho e aos de grupos ligados ao mercado, para que lado pende a balança; se pender para o empresariado, contra os trabalhadores, mesmo que as condições econômicas viabilizem uma estratégia inversa, então a política não deve ser vista como social-democrática.

Ao mesmo tempo, no interior dos partidos social-democratas, podem ser analisadas as disputas entre grupos em torno do caminho a ser adotado, identificando-se tanto aqueles que buscam uma manutenção do status quo, sem uma transformação favorável aos trabalhadores, como seus oponentes, 
os setores social-democratas (separando-se destes, entretanto, os segmentos dogmáticos presos unicamente ao discurso e distanciados da análise das condições reais para o avanço social-democrata).

Paralelamente, são objeto de pesquisa as medidas adotadas para, em um novo conflito de ideologias, deslocar a hegemonia, conquistando corações e mentes para uma nova situação mais favorável aos trabalhadores e para a condenação da exclusão e da mercantilização. A conquista da opinião pública é fundamental para a social-democracia, que dela depende para a obtenção de vitórias eleitorais consistentes o suficiente para levar adiante reformas profundas, que tenham um caráter cumulativo e estejam menos sujeitas a recuos futuros.

Esclareceria mais para entender os partidos social-democratas, portanto, um estudo sobre esforços específicos em cada país para se tentar modificar as condições que os restringem e, assim, poder retomar o avanço reformista. Esping-Andersen (1985) e Manin (1989) estão atentos a essa possibilidade de se adotarem políticas para modificar as condições existentes.

Lanzaro (2007, p. 19), apesar de ter realizado uma análise pouco consistente das esquerdas "populistas" na América Latina, ${ }^{7}$ mostrou-se ciente da relevância de se avaliar os governos social-democratas do ponto de vista de seu avanço no limite das possibilidades:

[...] cabe construir um ranking de alta, média ou baixa inovação, que sirva para avaliar o aproveitamento do capital político que deriva dessas alternâncias e nos deixe saber se essas esquerdas governantes estão à altura de suas próprias possibilidades. Por extensão, a investigação permitiria fazer referência às experiências europeias e, do mesmo modo, estabelecer comparações com os governos anteriores, que nos três países a que nos referimos [Brasil, Chile e Uruguai] impulsionaram um reformismo relativamente importante. Poderíamos saber, então, com certo fundamento empírico, se essas esquerdas - integradas à democracia política - delineiam efetivamente uma democracia social.

A questão do abandono ou da adesão ao capitalismo não é tão relevante, visto que talvez não seja possível determinar a priori se uma transição gradual do capitalismo para o socialismo, seja lá como este for definido, está ou não ocorrendo quando um governo realiza reformas pró-trabalho ou de controle e limitação do capital. ${ }^{8}$ Da mesma forma, interpretar a perda da ênfase na

7 Para uma crítica a essa abordagem, ver Reis e Vieira (2009).

8 Esping-Andersen (1985) faz argumento semelhante, ainda que utilize outra terminologia. Segundo ele, não se pode prever, no momento da realização de uma reforma, se ela terá ou não um efeito revolucionário. 
socialização dos meios de produção como mudança de objetivo ignora que o ponto central é a mudança da correlação e forças entre trabalho e capital e que a forma vista como adequada para promovê-la é conjunturalmente condicionada.

Kautsky e Bernstein, cada um a seu modo, pensaram em políticas específicas para a conjuntura que observavam. Obviamente, transplantálas para o presente, ao menos sem alterações, seria anacrônico. Aos socialdemocratas de hoje, cabe fazer o mesmo que eles, analisando as limitações, com atenção às oportunidades de avanço, e sempre com a política institucional eleitoral e parlamentar como um lócus incontestável. A luta para transformar esses limites, inclusive com o estabelecimento de uma nova hegemonia, tem papel não menos fundamental. Aos analistas, por sua vez, cabe buscar métodos de avaliar se os avanços nos projetos social-democratas estão ocorrendo no limite das possibilidades ou se governos e partidos classificados como socialdemocratas não fazem jus a esse rótulo.

\section{Referências}

ANDREUCCI, Franco. A difusão e a vulgarização do marxismo. In: HOBSBAWM, Eric J. et al. História do Marxismo 2: O Marxismo na época da Segunda Internacional. Rio de Janeiro: Paz e Terra, 1982. p. 15-73.

BERNSTEIN, Eduard. Socialismo evolucionário. Rio de Janeiro: Jorge Zahar, 1997.

CAMILLER, Patrick. Espanha: Sobrevivência do socialismo? In: ANDERSON, Perry; CAMILLER, Patrick (orgs.). Um mapa da esquerda na Europa Ocidental. Rio de Janeiro: Contraponto, 1996.

COELHO, Roseli Martins. Social-democracia: formas e reformas. São Paulo: Humanitas, 2001.

DOWNS, Anthony. Uma teoria econômica da democracia. São Paulo: Edusp, 1999.

ESPING-ANDERSEN, Gøsta. Politics against markets: the social democratic road to power. Princeton: Princeton University Press, 1985.

$\frac{}{1990 .}$. The three worlds of welfare capitalism. Princeton: Princeton University Press,

FETSCHER, Iring. Bernstein e o desafio à ortodoxia. In: HOBSBAWM, Eric J. et al. História do Marxismo 2: O Marxismo na época da Segunda Internacional. Rio de Janeiro: Paz e Terra, 1982. p. 257-298.

KAUTSKY, Karl. The class struggle: Erfurt Program. Nova York: W. W. Norton \& Company, 1971.

A Ditadura do Proletariado. In: KAUTSKY, K. e LENIN, V. I.. Kautsky: a ditadura do proletariado; Lenin: a revolução proletária e o renegado Kautsky. São Paulo: Livraria Editora Ciências Humanas, 1979. p. 1-87. 
KIRCHHEIMER, Otto. The transformation of Western European party systems. In: LAPALOMBARA, J.; WEINER, M. (eds.). Political parties and political developments. Princeton: Princeton University Press, 1966. p. 177-200.

KITSCHELT, Herbert. Organization, strategy, and elections. In: The logics of party formation: Ecological politics in Belgium and West Germany. Ithaca e Londres: Cornell University Press, 1989. p. 41-74.

KLOPPENBERG, James T. Uncertain victory: social democracy and progressivism in European and American thought, 1870-1920. Nova York: Oxford University Press, 1986.

LANZARO, Jorge. Gobiernos de izquierda en América Latina: entre el populismo y la social democracia - Una tipología para avanzar en el análisis comparado. Análise de Conjuntura - Observatório Político Sul-Americano, Rio de Janeiro, n. 2, dez. 2007. [Online]. Disponível em: <http://www.opsa.com.br/images/pdf/analise/40_analises AC_n_12_dez_2007.pdf $>$. Acesso em: 29 set. 2011.

LENIN, Vladimir I. A Revolução proletária e o renegado Kautsky. In: KAUTSKY, K. e LENIN, V. I. Kautsky: a ditadura do proletariado; Lenin: a revolução proletária e o renegado Kautsky. São Paulo: Livraria Editora Ciências Humanas, 1979. p. 89-181.

MANIN, Bernard. Démocratie, pluralisme, libéralisme. In: BERGOUNIOUX, Alain e __. Le régime social-démocrate. Paris: Presses Universitaires de France, 1989. p. $23-55$.

MARLIÈRE, Philippe. A batalha de Londres: face autoritária da "terceira via". Biblioteca Diplô, São Paulo, maio 2000. [Online]. Disponível em: <http://diplo.org. br/imprima1744>. Acesso em: 29 set. 2011.

NETTL, J. P. Social democracy in German and revisionism. In: WIENER, Philip P. (ed.). The dictionary of the history of ideas. Nova York: Charles Scribner's Sons, v. 4, 1973-74. p. 264-276.

PANIZZA, Francisco E.. The social democratisation of the Latin American left. Revista Europea de Estudios Latinoamericanos y del Caribe, n. 79, p. 95-103, out. 2005.

PRZEWORSKI, Adam. A social-democracia como um fenômeno histórico. In: Capitalismo e Social-democracia. São Paulo: Companhia das Letras, 1989. p. $\overline{19-65 .}$

REIS, Guilherme Simões. A disputa político-partidária no Uruguai: oponentes externos, adversários internos. Observador on-line, Rio de Janeiro, v. 6, n. 3, mar. 2001. [Online]. Disponível em: <http://www.opsa.com.br/images/pdf/observador/78 observador_topico_Observador_v_6_n_3.pdf>. Acesso em: 29 set. 2011.

REIS, G. S.; VIEIRA, Soraia Marcelino. Left-Wing populists in Latin America?: an analysis of the Chávez and Morales governments. Trabalho apresentado no 21응 Congresso Mundial de Ciência Política, em Santiago do Chile, 2009. [Online]. Disponível em: <http://paperroom.ipsa.org/papers/paper_1080.pdf>. Acesso em: 10 jul. 2011.

RIKER, William H. Liberalism against populism: a confrontation between the theory of democracy and theory of social choice. São Francisco: W. H. Freeman, 1982. 
SADER, Emir (org.). Gramsci: poder, política e partido. São Paulo: Expressão Popular, 2005.

SALVADORI, Massimo L. Kautsky entre ortodoxia e revisionismo. In: HOBSBAWM, Eric J. et al. História do Marxismo 2: O Marxismo na época da Segunda Internacional. Rio de Janeiro: Paz e Terra, 1982. p. 299-339.

SINGER, André. O PT. São Paulo: Publifolha, 2001.

STRØM, Kaare; MÜLLER, Wolfgang C. Political parties and hard choices. In: MÜLLER, W. C. ; STRØM, K. (eds.). Policy, office or votes?: how political parties in Western Europe make hard decisions. Cambridge: Cambridge University Press, 1999. p. 1-35.

WALDENBERG, Marek. A estratégia política da social-democracia alemã. In: HOBSBAWM, Eric J. et al. História do Marxismo 2: O Marxismo na Época da Segunda Internacional. Rio de Janeiro: Paz e Terra, 1982. p. 223-255.

Data de recebimento: 10/07/2011.

Data de aprovação: 20/11/2011. 